This item was submitted to Loughborough's Research Repository by the author.

Items in Figshare are protected by copyright, with all rights reserved, unless otherwise indicated.

\title{
A new fatigue test procedure for die-casting tool materials
}

PLEASE CITE THE PUBLISHED VERSION

PUBLISHER

Professional Engineering Publishing / @ IMechE

VERSION

VoR (Version of Record)

LICENCE

CC BY-NC-ND 4.0

REPOSITORY RECORD

Norwood, Andrew J., Phill M. Dickens, Rupert C. Soar, and Russell A. Harris. 2019. "A New Fatigue Test Procedure for Die-casting Tool Materials”. figshare. https://hdl.handle.net/2134/4715. 
This item was submitted to Loughborough's Institutional Repository (https://dspace.lboro.ac.uk/) by the author and is made available under the following Creative Commons Licence conditions.

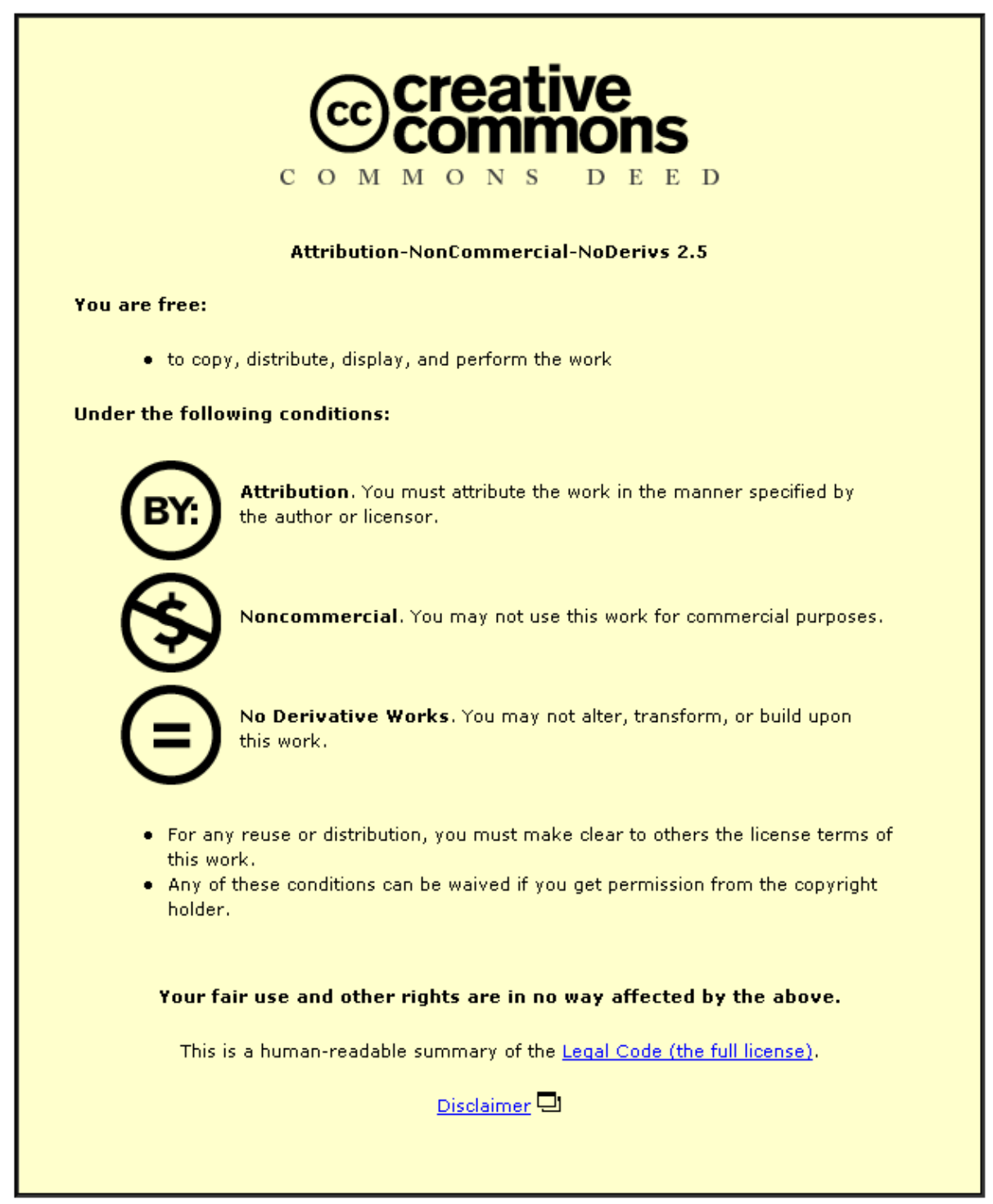

For the full text of this licence, please go to: http://creativecommons.org/licenses/by-nc-nd/2.5/ 


\title{
A new fatigue test procedure for die-casting tool materials
}

\author{
A J Norwood, P M Dickens*, R C Soar, and R A Harris \\ Wolfson School of Mechanical and Manufacturing Engineering, Loughborough University, Loughborough, UK \\ The manuscript was received on 20 November 2006 and was accepted after revision for publication on 6 March 2007.
}

DOI: 10.1243/09544054JEM787

\begin{abstract}
The objective of this research was to investigate a new test procedure for simulating the temperatures in die casting so that materials can be evaluated as tool materials for the high-pressure die casting of aluminium. Other procedures have been used for evaluating the thermal fatigue performance of tool materials, but these tests do not reproduce all the conditions found in production environments. A new test method has been established that enables the thermal fatigue resistance of materials to be identified. The test is robust, reliable, and versatile and has a large operating temperature range $\left(25-1200^{\circ} \mathrm{C}\right)$, and the cycle times and dwell times are adjustable. The results have shown a similar number of cycles to induce the same level of fatigue cracking as in actual die-casting tools. The performance of different materials can be compared, and an approximate fatigue life for high-pressure die-casting tools can be determined.
\end{abstract}

Keywords: die casting, thermal fatigue, tool

\section{DIE CASTING}

In cold-chamber die casting, aluminium alloys are injected at $700-750{ }^{\circ} \mathrm{C}$ depending on the die geometry. The die is typically water cooled, and the surface is sprayed with a water-based die lubricant. The molten material is forced into the die via a hydraulic plunger/piston in three controlled phases.

1. Phase 1 is termed take up and slowly pushes the aluminium towards the die with reduced turbulence.

2. Phase 2 is the injection phase and has to be fast enough to prevent chilling while the alloy is filling the die. The speed of this phase is approximately $10 \mathrm{~m} / \mathrm{s}$ and typically takes $0.05-0.1 \mathrm{~s}$ [1] .

3. Phase 3 is the compaction phase - as the alloy solidifies in the cavity it begins to shrink away from the surface of the die. The force applied to the alloy $\left(50-70 \mathrm{~N} / \mathrm{mm}^{2}\right)$ reduces this effect and reduces the size of inclusions and porosity caused by air trapped during injection.

\footnotetext{
*Corresponding author: School of Mechanical and Manufacturing Engineering, University of Loughborough, Loughborough, Leicestershire LE11 3TU, UK. email: p.dickens@lboro.ac.uk
}

The dies are subject to fluctuating temperatures owing to the injection of molten metal and then rapid cooling by part ejection and the application of die lubricant. This process causes the die to undergo thermal fatigue and eventually fail. The rate of failure is dependent upon the cycle time and the type of alloy being cast; alloys with a high melting point have a greater thermal shock on steel dies $[\mathbf{2}, \mathbf{3}]$. Thermal fatigue is costly for die casters as it causes downtime, loss of production, the need for die repairs, etc. Obtaining an understanding of how materials perform and fail when subjected to thermal fatigue is important for die casters $[\mathbf{4}, \mathbf{5}]$.

Die design and material selection is crucial as it affects the performance and the life of dies. A small radius $(0.5-1 \mathrm{~mm})$ or a large change in the die thickness can cause accelerated thermal fatigue as they act as stress concentrators/crack initiators. H13 is commonly used in industry for the manufacture of aluminium high-pressure die-casting dies $[\mathbf{3}, \mathbf{6}, \mathbf{7}]$.

\subsection{Temperature within a high-pressure die-casting tool}

Previous work by one of the present authors [8] has shown that the thermal cycle of the high-pressure die casting of aluminium is as shown in Fig. 1. 


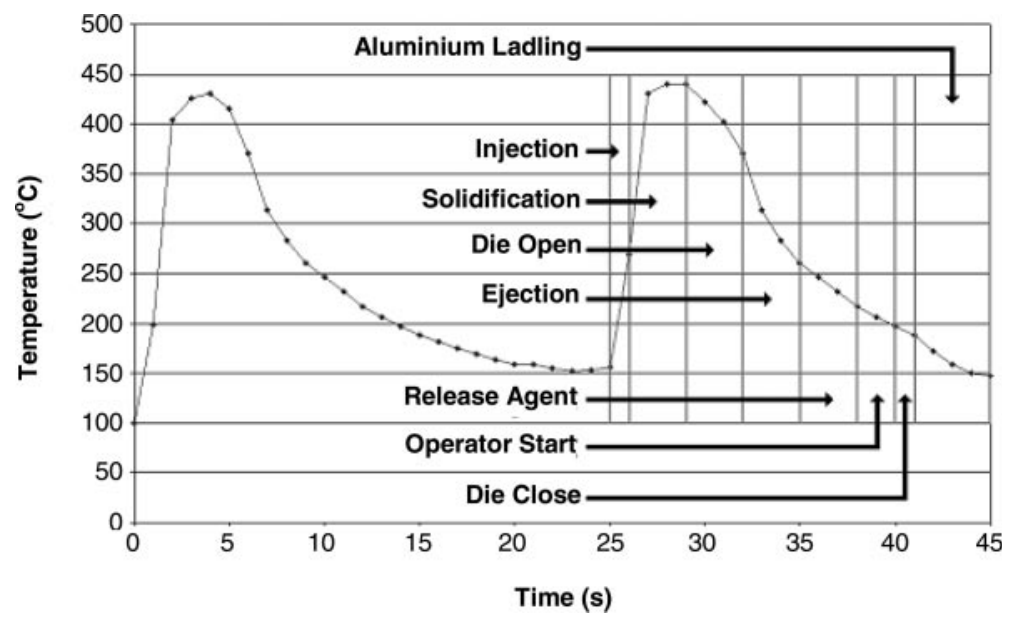

Fig. 1 Aluminium high-pressure die-casting thermal cycle

\subsection{Die failure}

There are three basic categories of failure associated with die-casting dies, these being erosion, physical wear, and thermal fatigue [9]. Thermal fatigue causes most of the problems with regards to tool life and is greatly affected by surface conditions such as microstructure, hardness, surface finish [10], residual stresses, etc.

The formation of cracks is associated with the accumulation of local plastic strain that occurs during each casting cycle. Initial crack growth is facilitated by oxidation of the crack surfaces, and proceeding growth is facilitated by this oxidation in combination with crack filling of the cast material, and by softening of the tool material [11]. Initially, molten metal contacts the die and causes the surface temperature to increase above that of the interior of the die [9]. The die face starts to expand; however, the cooler underlying layer resists this expansion, creating a temporary compressive stress layer $[\mathbf{1 2}$, 13]. When the casting is removed, the die surface starts to cool and, as it does so, the surface shrinks or contracts. The surface cools more quickly than the interior of the die, which places the subsurface of the die into residual tensile stress, which is made worse by the application of die lubricant [14]. During further cycling, the die surface is subjected to alternating compressive and tensile stresses that result in plastic deformation [15]. Continued cycling reduces the yield strength of the tool, causing increased residual tensile stresses to develop and cracks to initiate. This type of cracking is more prevalent in aluminium and brass die casting because of the higher temperatures and resulting thermal shock by the molten metal. The heat cracking performance is improved by careful tool steel selection, proper heat treatment, and preventive maintenance measures [16].

Another factor affecting thermal fatigue is, of course, the cycle time or time spent subjected to either hot or cold conditions. The maximum temperature in the thermal fatigue cycle is considered to be the most important since it is related to the reduction in the mechanical properties (yield point) and higher deformation. The temperature also affects the way in which the crack initiates and grows; high temperatures can cause recrystallization, relaxation of stresses by creep, etc. $[\mathbf{1 7}, \mathbf{1 8}]$.

Surface roughness also plays a role. Decreasing the surface roughness from 0.63 to $0.16 \mu \mathrm{m}$ has been shown to increase the thermal fatigue resistance of materials by $40-50$ per cent.

\subsection{Die life expectancy}

The life of an $\mathrm{H} 13$ die in terms of the number of parts that can be made under production conditions will depend upon the alloy used, the product features required, and the tolerances to be maintained on those features. The required surface finish and the final specifications for the cast surface have an important impact on die life. Typically, an aluminium die will produce $100000-150000$ castings, a magnesium die 3-5 times more, and a zinc die can typically produce a larger number.

\section{THERMAL FATIGUE TESTING}

To understand how a material behaves when subjected to thermal fatigue, it is important to simulate the process thermal cycle in which it is to be used. This is achieved by assessing the process and developing a test that simulates the process temperature cycle (heating rate, cooling rate, temperature difference, maximum temperature, cycle duration, etc.).

There are several forms of thermal fatigue test, for example, forced convection methods, conduction methods by immersion in liquids, radiation, quartz 
lamp [19], induction [20-22], resistance [23], immersion in fluidized solids (fluidized bed), etc.

The forced convection method involves subjecting the specimen to a blast of hot or cold gas with suitable velocity and pressure. The problem with this method is that large quantities of fuel are required to test specimens with a moderate-size flame, which is typically followed by an air blast, and so it is expensive [24]. An additional drawback is that the flow over the specimen needs to be uniform in order to maintain constant heat transfer coefficients.

Immersion in liquid is a common method used to induce fatigue damage and is carried out by immersing specimens in molten metals or salts. During immersion, heat transfer occurs by conduction. The contact layers of the specimen and molten medium initially reach a common temperature established by the ratio of their thermal conductivities. The large temperature gradient that occurs at the surface layer of the testpiece during this time causes high stress generation, but this method causes the specimen to be heated rapidly. The heat-up rate is reduced if heating occurs by convection because of the low conductivity of air, and hence a lower initial thermal gradient results. A material can be affected by the difference between heating methods in terms of the extent and dispersal of the stresses [24]. There is also a limited choice of liquids available to heat specimens since the melting point must be higher than the final temperature of the specimen interface to prevent heat transfer problems caused by brief freezing of the liquid to the specimen surface. The metal or salts present may also cause corrosion/erosion effects. Rapid cooling of specimens into liquids such as water, brine, etc., results, initially, in localized boiling and vapour on the specimen surface. As the specimen cools, the vapour begins to dissipate, causing sporadic contact between the specimen surface and the liquid; this hinders the heat transfer and may not provide an acceptable thermal shock.

Heating of a specimen can be achieved by radiation. However, in order to obtain the required heating rate it is necessary for the radiating surface to be set at a higher temperature to achieve the desired specimen surface temperature. For example, Glenny et al. [24] state that, to achieve rapid heating to $1000^{\circ} \mathrm{C}$, a radiating surface of $1400^{\circ} \mathrm{C}$ is required. After initial heating in a furnace, set at $1400^{\circ} \mathrm{C}$, the specimen would have to be transferred, once the surface temperature reaches $1000{ }^{\circ} \mathrm{C}$, to a second furnace set at $1000^{\circ} \mathrm{C}$. Quartz lamps are typically more economical at lower temperatures because they offer uniform heating over different areas of the specimen. However, they do have slow cooling rates, and forced cooling is required when they are used [25].

Induction heating allows good control of the heating rate and maximum temperature. However, as with radiation heating, the heat input needs to be varied in order firstly to achieve the desired heating rate and then to maintain the desired temperature. Castelli and Ellis [26] used a series of three independently controlled coils, allowing a systematic approach to temperature modification at localized points along the specimen; this approach enables complex specimen geometries to be used, but it is expensive [25].

Fluidized beds have been used extensively to heat and cool specimens. A fluidized bed consists of a container with a porous bottom through which a gas can flow to fluidize a powder.

\subsection{Wallace thermal fatigue test}

The Wallace dunk test has been used widely at Case Western Reserve University to measure the thermal fatigue resistance of die steels. The test measures average maximum crack length and total crack area on the four corners of a specimen after a set number of cycles of immersion into a bath of molten aluminium at $730^{\circ} \mathrm{C}$. The specimen is internally water cooled and has a high thermal gradient with sharp corners of $0.01^{\prime \prime}(0.254 \mathrm{~mm})$ radius. The test has been used for 30 years, and the results correlate well with the service performance of die-casting die materials [4].

The specimen dimensions are $50.8 \mathrm{~mm} \times 50.8 \mathrm{~mm} \times$ $117.8 \mathrm{~mm}\left(2^{\prime \prime} \times 2^{\prime \prime} \times 7^{\prime \prime}\right)$, with a $\emptyset 38.1 \mathrm{~mm}\left(\emptyset 1.5^{\prime \prime}\right)$ hole in the centre for internal water cooling. The outer surface of the specimen is sprayed with a waterbased lubricant before entering the aluminium. Water is passed through the specimen at 3.5 gallons (USA gallons) $(13.25 \mathrm{~L})$ per minute. The molten aluminium is maintained at $730^{\circ} \mathrm{C}$ and the specimen is immersed for $12 \mathrm{~s}$, removed, and air cooled for $24 \mathrm{~s}$, and then sprayed with die lubricant for a further $4 \mathrm{~s}$. Wallace's procedure involves 5000 thermal cycles before measuring the cracks, it is then repeated every 5000 cycles up to a total of 15000 cycles, and then termination of the test occurs.

Wallace has tested many die materials and surface treatments with the aim of improving die life. In the die casting industry, premium-grade $\mathrm{H} 13$ is used to produce dies, and hence all materials studied are compared with it [5].

\subsection{Glenny thermal fatigue test}

Glenny designed a fluidized bed thermal fatigue test to evaluate materials for turbine blades. Heat transfer in a fluidized bed of aluminium oxide sand was achieved by electric elements heating the powder particles. These particles then transfered heat to one another, aided by the gas flow. It is also possible to 
cool the material using a fluidized bed [27], giving rise to a controllable thermal fatigue medium.

In the work by Glenny the specimens employed were tapered discs, which permitted a convenient method of evaluating thermal fatigue behaviour because the cracks initiated at the edges and were easily measured. During the test, the disc specimens were subjected to alternate heating and cooling shocks by transferring them between hot and cold fluidized beds of aluminium oxide sand. The specimens in the early work were designed to represent the thickness and edge radius of a typical turbine blade [24].

Mowbray and McConnelee [28] conducted a study of the Glenny specimen shape and method of heating and cooling to determine the stress and strain on a disc. In the tests the cooling bath was held at $21^{\circ} \mathrm{C}$ for an exposure time of $4 \mathrm{~min}$. The hot bath temperature was varied between 815 and $1035^{\circ} \mathrm{C}$ with exposure times of 1 or $4 \mathrm{~min}$. The material tested was a cast cobalt-base superalloy, FSX414. In the initial seconds of each shock the maximum temperature change developed at the disc extremities, and in turn the maximum strain also occurred at this location.

\subsection{Persson thermal fatigue test}

Persson [11] and Persson et al. [22, 29, 30] developed a thermal fatigue test to simulate the temperature found in his previous work. Thermal fatigue cracking was produced on the surface of test rods by simulating the rapid alternating temperature conditions using cyclic induction heating and internal cooling of hollow cylindrical test rods $(\varnothing 10 \mathrm{~mm}$, length $80 \mathrm{~mm}$ with a $\emptyset 3 \mathrm{~mm}$ cooling channel in the centre). Surface strain was also measured using a non-contact laser speckle technique. In a typical test, the induction unit $(25 \mathrm{~kW}, 3 \mathrm{MHz})$ heated approximately $20 \mathrm{~mm}$ of the middle of the test rod. The cooling channel was continually supplied with silicon oil $(2.5 \mathrm{~L} / \mathrm{min})$ at $60^{\circ} \mathrm{C}$ and cooled externally with argon or air. The external cooling also decreased oxidation. During the test, a pyrometer and a K-type thermocouple measured the specimen temperature [11].

When thermal fatigue testing hot-work tool steel grades QRO 90 and Supreme and Hotvar $700^{\circ} \mathrm{C}$, Persson found that a typical crack network occurred after 10000 cycles, with considerable softening of the tool materials. Persson estimated that the tensile stresses during the test never exceeded the yield strength of the steel. However, numerous cracks formed within the low-cycle fatigue range. Low-cycle fatigue occurs at a relatively small number of cycles, or stress applications. The number of cycles may be in the tens, hundreds, or even thousands. Low-cycle fatigue conditions prevail when considerable plastic deformation occurs. There is no exact dividing line between low-cycle and high-cycle fatigue, but, many define low-cycle fatigue as that occurring in 50000 cycles or less [31]. High-cycle fatigue occurs at a relatively large number of stress cycles and is not accompanied with plastic deformation but instead is dominated by elastic deformation [30].

\subsection{Limitations of existing test procedures}

There are many disadvantages associated with existing thermal fatigue processes.

1. In Wallace's test the sample is large and so the power requirements are high for heating and cooling, and also the heat loss from the furnace is high.

2. In Wallace's test there is a need to polish the samples before analysis. This can change the surface roughness and affect future crack initiation.

3. Glenny's thermal fatigue test was designed to test materials for turbine blade suitability and not die casting. This is reflected in the cycle times, which can be as high as 4 min heating and 4 min cooling.

4. Persson's sample makes it difficult to measure crack length as it only shows surface cracking.

5. The present authors believed that neither Wallace's nor Persson's test was representative of pressure die casting. Wallace's test dunks the specimen into molten aluminium at $730{ }^{\circ} \mathrm{C}$ for $12 \mathrm{~s}$ and heats the specimen corners to $704^{\circ} \mathrm{C}$, and cracks occur in $\mathrm{H} 13$ die steel at 15000 cycles. This is not a correct temperature profile as dies do not heat up to $704{ }^{\circ} \mathrm{C}$ and are not subjected to that temperature for $12 \mathrm{~s}$, and $\mathrm{H} 13$ dies do not typically initiate cracking until 100000 cycles. Persson's test caused cracking of die steel at 20000 when tested at $600^{\circ} \mathrm{C}$, again not representing the die-casting temperature profile.

\subsection{Advantages of existing test procedures}

There are advantages with some elements of the processes.

1. Glenny's sample has a small radius and changing cross-section (typical features in a die).

2. Glenny's sample has no water flowing through it, unlike Wallace's and Persson's tests. Some tooling materials (especially those that are sintered) may be porous and could be dangerous if water contacts molten aluminium or furnace elements.

\section{DESIGN OF A NEW TEST PROCEDURE}

In view of the fact that previous tests had not met the desired requirements, a new procedure was seen to 

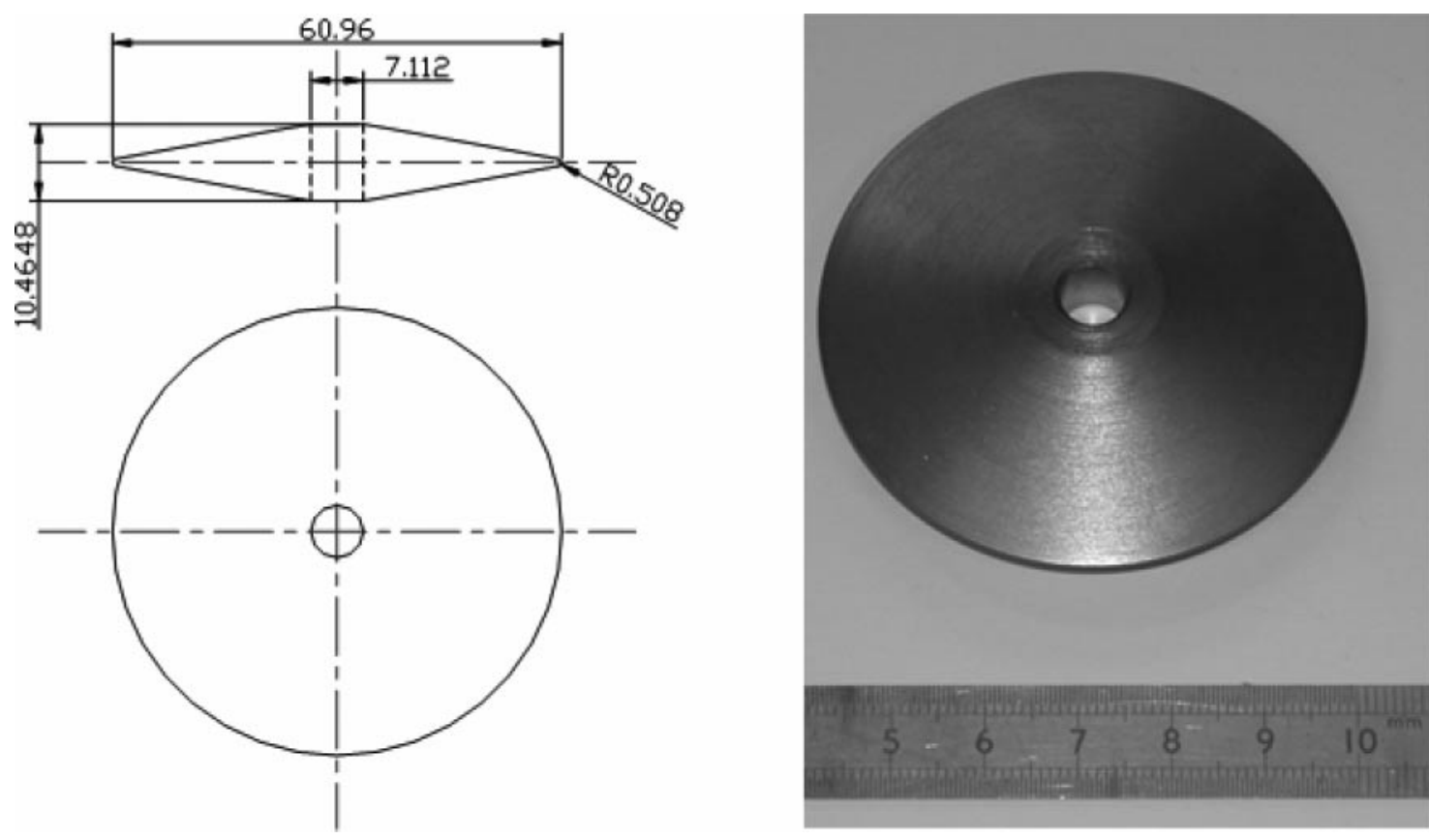

Fig. 2 Disc design (dimensions in $\mathrm{mm}$ )

be required to produce a thermal profile similar to that in Fig. 1.

\subsection{Design of the specimen}

It was decided to use the disc-shaped specimen provided by Glenny [24] as the sample size was small, which would reduce power requirements and would also enable testing of several specimens simultaneously. As the sample was solid and not water cooled, there would also be no problem with porous tool materials. Glenny's specimen also had a small edge radius of $0.5 \mathrm{~mm}$, which is typically the smallest expected on a die. The specimen also had a change in cross-section, which also occurs in dies, making it a suitable specimen geometry. The discs (Fig. 2) were designed to initiate cracks at the edge radius and allow for ease of measurement.

Testing several specimens simultaneously (Fig. 3) would allow accurate validation of results. H13 (AISI) for the specimens was provided by Bohler, and the composition can be seen in Table 1. The specimens were heat treated to a hardness of between HRC 43 and HRC 45.

\subsection{Design of thermal fatigue apparatus}

To conduct accurate material evaluation, a reliable experimental apparatus and reproducible procedure needed to be developed. A heating medium, a cooling medium, and an automated transfer system were required. The transfer apparatus shown in Fig. 4 was designed to be versatile, allowing adjustments to be made in the positioning of the specimens. The
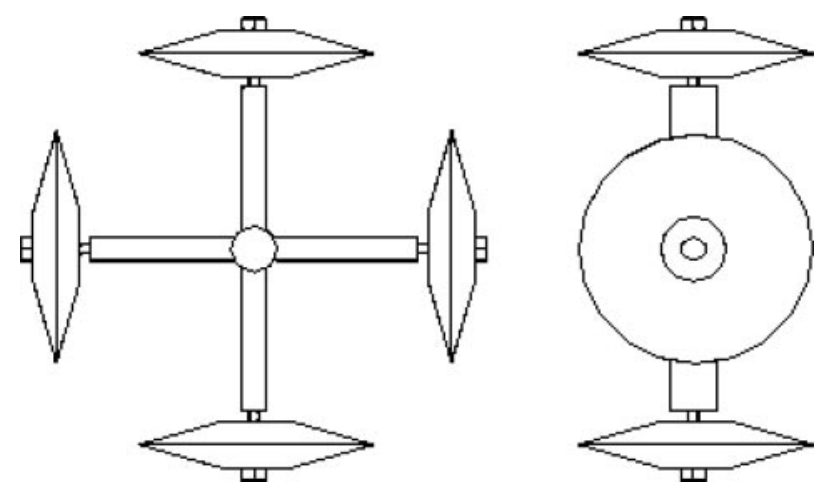

Fig. 3 Multiple specimen test arrangement

Table 1 H13 composition

\begin{tabular}{llllllll}
\hline & \multicolumn{7}{c}{ Composition $(\mathrm{Wt} \%)$} \\
\cline { 2 - 7 } & $\mathrm{Fe}$ & $\mathrm{C}$ & $\mathrm{V}$ & $\mathrm{Si}$ & $\mathrm{Ni}$ & $\mathrm{Cr}$ & Mo \\
\hline $\mathrm{H} 13$ & Bal. & - & 1.3 & 1.2 & 0.1 & 5.3 & 1.3 \\
\hline
\end{tabular}

basic design consisted of a steel frame with $X$ and $Z$ axis pneumatic actuators. An additional frame was fabricated connecting the $Z$ piston to the specimen holder to prevent heat being transferred and damaging the actuator and the electronics.

\subsection{Cooling the samples}

Since dies have internal water/oil cooling channels and die casters use a water-based lubricant to act as 


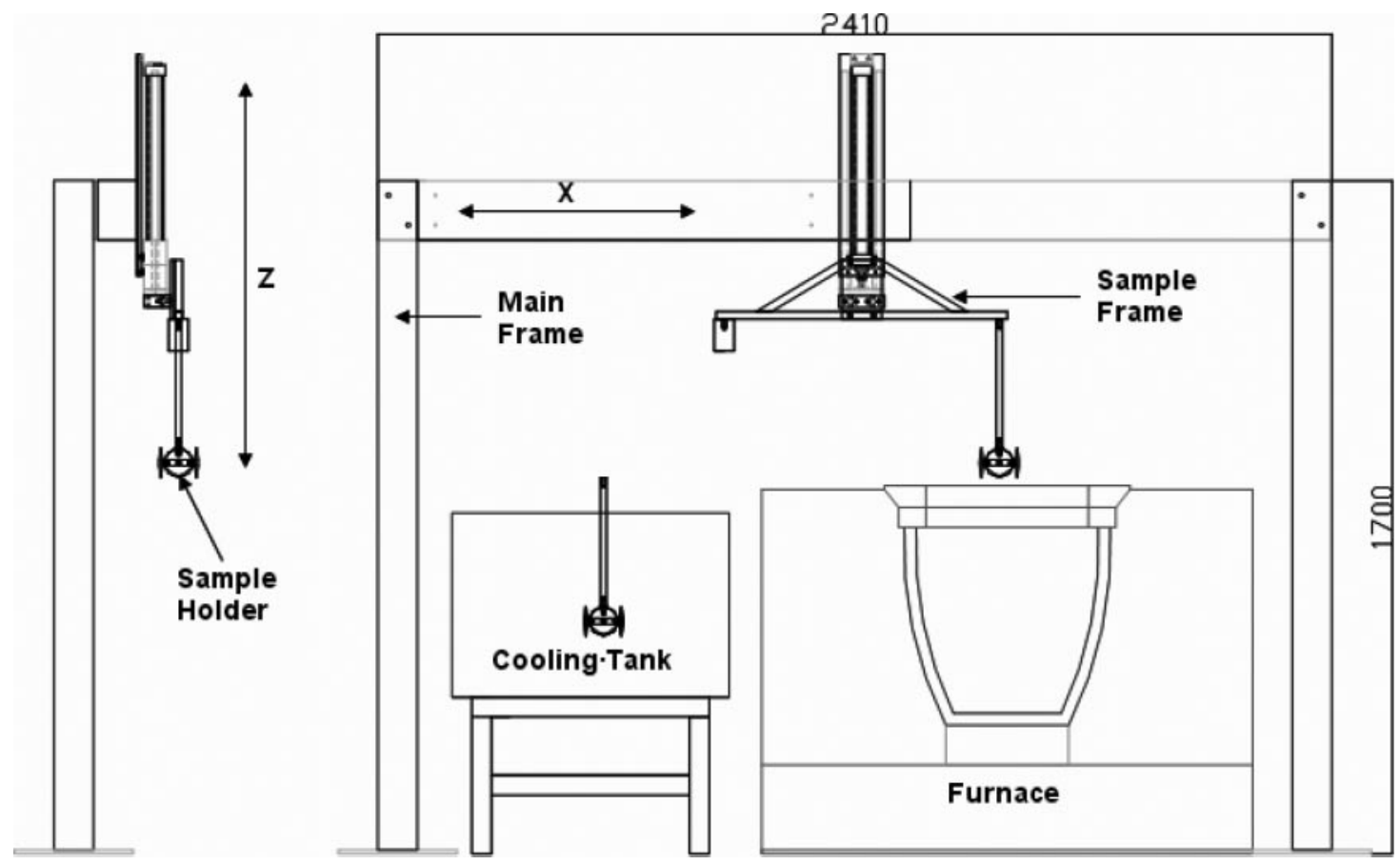

Fig. 4 Thermal fatigue apparatus design

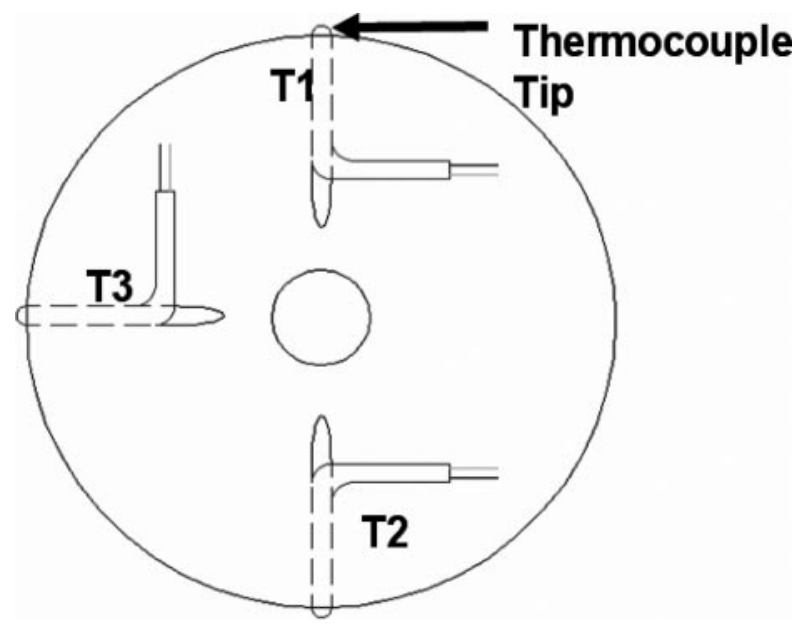

Fig. 5 Thermocouple location in specimen

a coolant and release agent on the surface of the die, water was also used to cool the specimen in the thermal fatigue experiments. The cooling medium tank was designed to have constant cooling. The temperature was controlled through a series of copper pipes circling the edge of the tank; this was connected to a chiller system. Over a $1 \mathrm{~h}$ thermal cycling period the tank maintained a steady water temperature between $11^{\circ} \mathrm{C}$ and $14^{\circ} \mathrm{C}$.

\subsection{Reproducing the thermal cycle}

These tests were designed to determine the most suitable method of heating and cooling. Three fibreglass-insulated K-type open-ended thermocouples, with a wire diameter of $0.3 \mathrm{~mm}$, were positioned at the edge of one specimen (Fig. 5).

The furnace used for the tests was capable of operating between 20 and $1200{ }^{\circ} \mathrm{C}$. Tests conducted with a calibrated thermocouple on the empty furnace showed that it could maintain temperature to within $\pm 10^{\circ} \mathrm{C}$.

\subsection{Thermal profile when heating specimens in a fluidized bed}

A fluidized bed was created by positioning an air distributor at the bottom of the furnace with F0885 aluminium oxide sand (supplied by Techne Ltd).

\subsubsection{Results}

After a series of preliminary tests it was found necessary to set the furnace at a very high temperature to maintain the desired specimen edge radius temperature with the cycle time set to $30 \mathrm{~s}$ and the water temperature set and maintained below $20^{\circ} \mathrm{C}$. This method of heating was not ideal because at the start of each test the specimen edge radius heated to approximately $1000^{\circ} \mathrm{C}$. This edge radius temperature eventually decreased and a stable profile was attained after $3600 \mathrm{~s}$ or 120 cycles. The problem arose because the furnace was unable to maintain temperature once the cold compressed air was passed through the sand, and in turn the specimens were removing heat from the furnace on every 


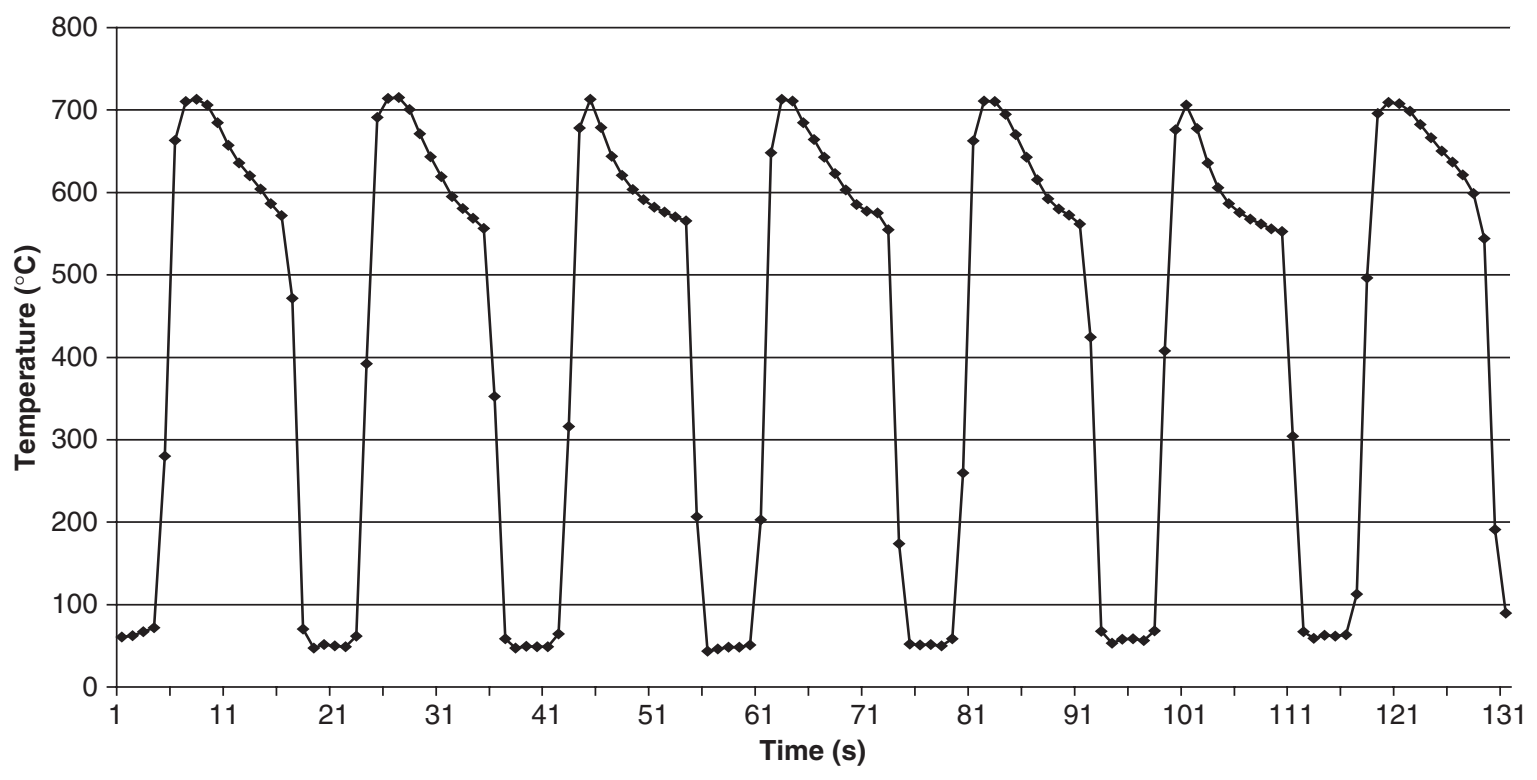

Fig. 6 Aluminium temperature profile

cycle, resulting in the system stabilizing after $1 \mathrm{~h}$. An additional problem occurred when small quantities of the fluidized sand became airborne and were deposited on the thermal fatigue transfer apparatus, causing severe wear and resulting in the replacement of the $X$ axis cylinder.

To reduce the temperature loss in the fluidized bed, the input air was preheated to $400{ }^{\circ} \mathrm{C}$ by passing the air supply through pipes in a muffle furnace $\left(20-1000^{\circ} \mathrm{C}\right)$. The oven temperature was reduced to $900{ }^{\circ} \mathrm{C}$, but it still took approximately $4000 \mathrm{~s}$, or 133 cycles, for the temperature to drop to a steady temperature. Again, the time to reach a steady state was not acceptable since the specimens would experience different thermal cycles at the initiation of each thermal fatigue test. A further concern of the heated air and fluidized beds was reliability of the air distributor and loss of sand over a period of time, making it an unsuitable method.

\subsection{Thermal profile when heating specimens in aluminium}

A $70 \mathrm{~kg}$ capacity crucible was placed in the furnace and filled with LM24 aluminium. The furnace was set at $750{ }^{\circ} \mathrm{C}$ and the cooling medium temperature was between $11^{\circ} \mathrm{C}$ and $15^{\circ} \mathrm{C}$.

The process maintained a stable temperature of $720^{\circ} \mathrm{C} \pm 10^{\circ} \mathrm{C}$ from the beginning of the test, with the surface of the specimens being subjected to $715^{\circ} \mathrm{C}$ (Fig. 6). The maximum temperature, however, could not be lowered since the aluminium had to remain molten, and hence the thermal shock could not be reduced.
The specimen surface was heated to over $600{ }^{\circ} \mathrm{C}$ in $2 \mathrm{~s}$, which was not representative - previous work had shown that it took approximately $2 \mathrm{~s}$ to reach only $400-450^{\circ} \mathrm{C}$. The maximum surface temperature obtained (over $700{ }^{\circ} \mathrm{C}$ ) was also too severe. A lower melting point material could have been used, but dipping in molten metals was not desirable because of the problem of solidification of the metal onto the specimens, which would affect the heat transfer and thermal profile.

\subsection{Thermal profile when heating specimens in furnace air}

The furnace was set at $1000{ }^{\circ} \mathrm{C}$ and the water was cooled to $20-25^{\circ} \mathrm{C}$; this ensured a constant thermal cycle with a maximum specimen temperature of $450-480^{\circ} \mathrm{C}$ and a 19 s cycle time.

The specimens were heated in the furnace for $8 \mathrm{~s}$, removed from the furnace and transferred to the cooling medium within $5 \mathrm{~s}$, and immersed in water for $1 \mathrm{~s}$, which was then followed by a $5 \mathrm{~s}$ transfer back to the furnace. The cycle achieved is shown in Fig. 7, and a single cycle is shown in Fig. 8(a). It is clear that the thermal cycle was not directly comparable with the thermal cycle recorded in the die as seen in Fig. 8(b).

The test showed that the desired temperature $\left(400-450{ }^{\circ} \mathrm{C}\right)$ was achievable, but the heating rate was slower than in a normal die, and the cooling rate was also faster. This fatigue test is more likely to cause cracking earlier than in the die, as the more rapid cooling is more likely to produce cracking. However, there is less thermal mass in the disc 


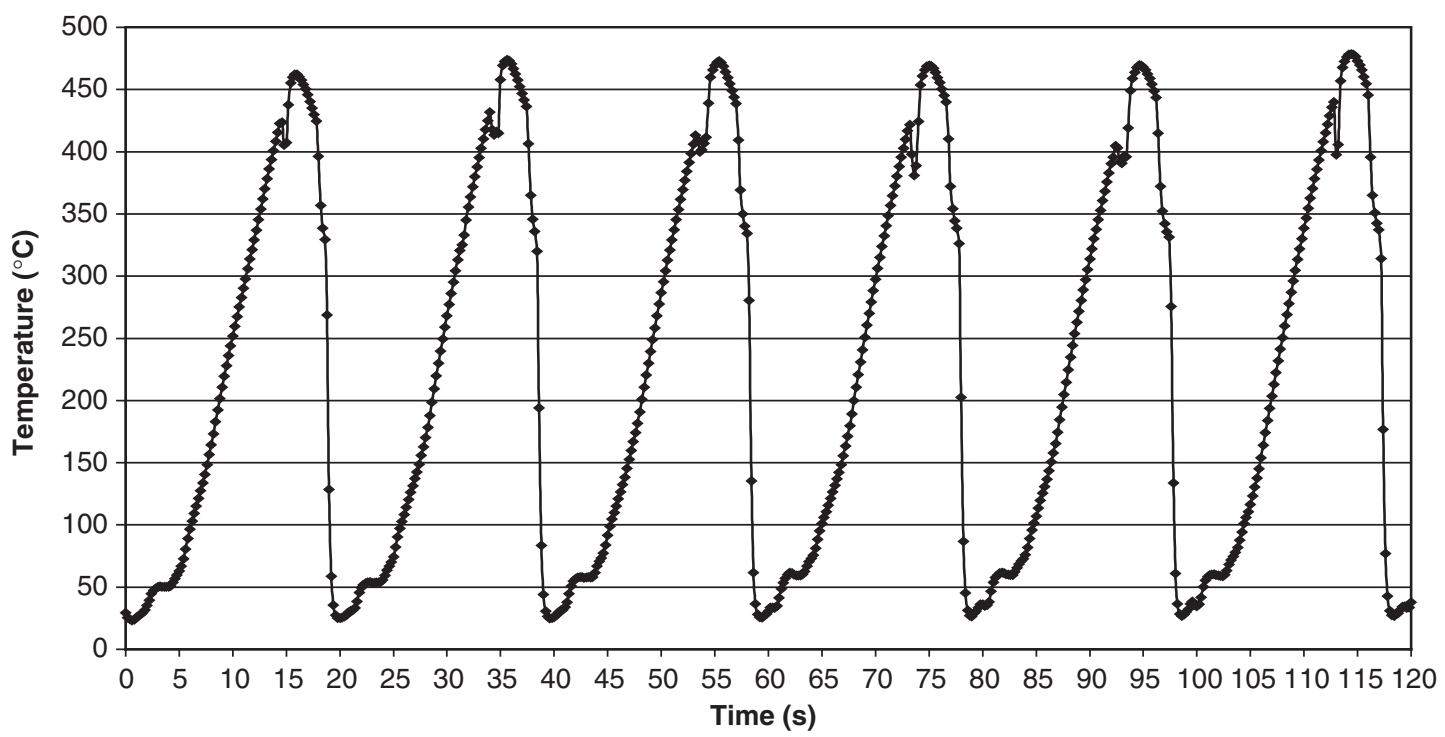

Fig. 7 Furnace experiment with air temperature profile
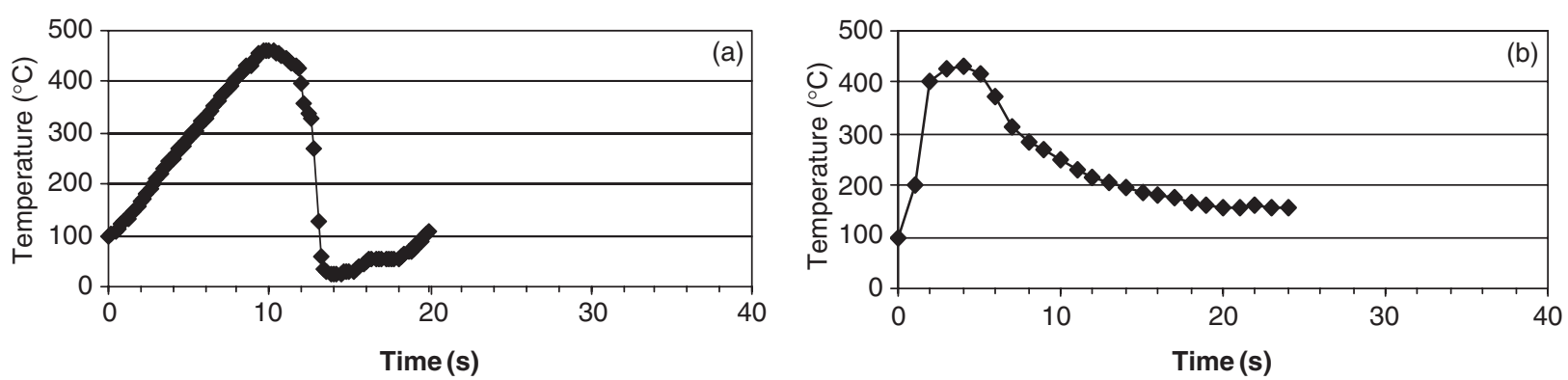

Fig. 8 (a) Single fatigue cycle and (b) desired thermal cycle from die experiments

than in a die, so the difference may not be very great. Therefore, it was thought likely to require a similar number of cycles to fatigue with $\mathrm{H} 13$ as in a production die.

\subsection{Temperature simulation conclusion}

The test apparatus was required to run non-stop for many hundreds of thousands of cycles, so it had to be durable. The fluidized bed and the aluminium heating methods both had problems with respect to their suitability as a means of heating the specimens. The fluidized bed experiments were not reliable owing to loss of sand, aggressive wear on the pneumatic actuators, and the time it took for the system to reach a stable temperature. The molten aluminium heating method was not chosen because the specimen temperature was too high and aluminium adhered to the specimen. Both methods were investigated because previous research into using these methods had been conducted by Wallace and Glenny, but an alternative, improved, heating method was required.

This led to a more controllable, reliable, and consistent method being adopted to simulate a thermal cycle. Although not exactly simulating the die-casting surface temperature, the materials would be subjected to the same temperatures experienced in a die. H13 specimens would also act as a reference and be used for comparison to assess the suitability of a die material.

\section{EVALUATING THE NEW THERMAL FATIGUE TEST PROCEDURE}

The H13 specimens were subjected to the new thermal fatigue test. After each set of cycles, the specimens were wiped clean using Viakal (Proctor and Gamble) to remove mineral deposits (limescale) and then optically inspected [21]. Optical analysis was chosen as it is quick, simple, and has an accuracy of $0.001 \mathrm{~mm}$. Each specimen was always repositioned on the apparatus in the same place and with the same orientation after the examinations. The test was repeated until sufficient thermal fatigue cracking was evident and recorded, or until the specimen was overwhelmed with cracks, making analysis difficult.

The number of thermal fatigue cycles for the $\mathrm{H} 13$ specimens was increased in increments of 10000 


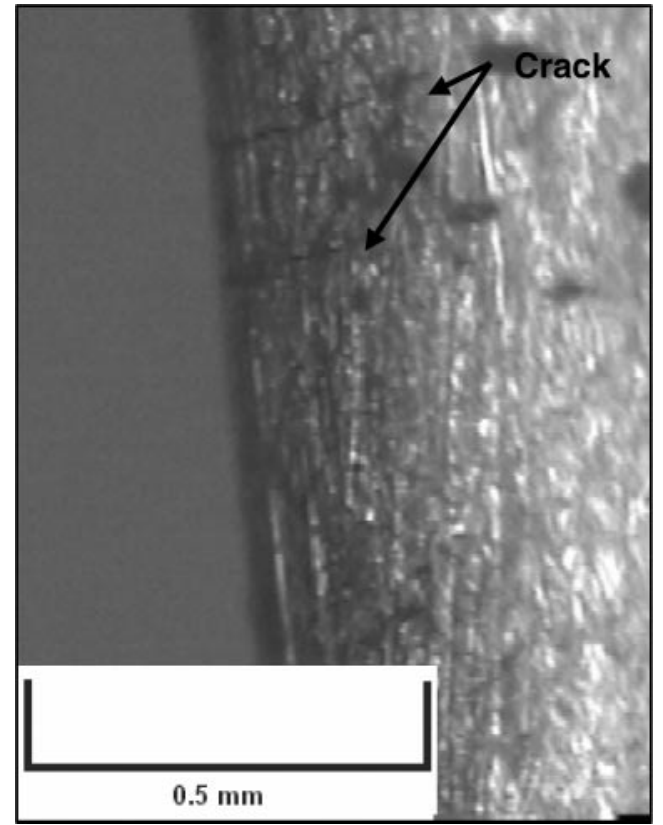

Fig. 9 Specimen after 180000 cycles

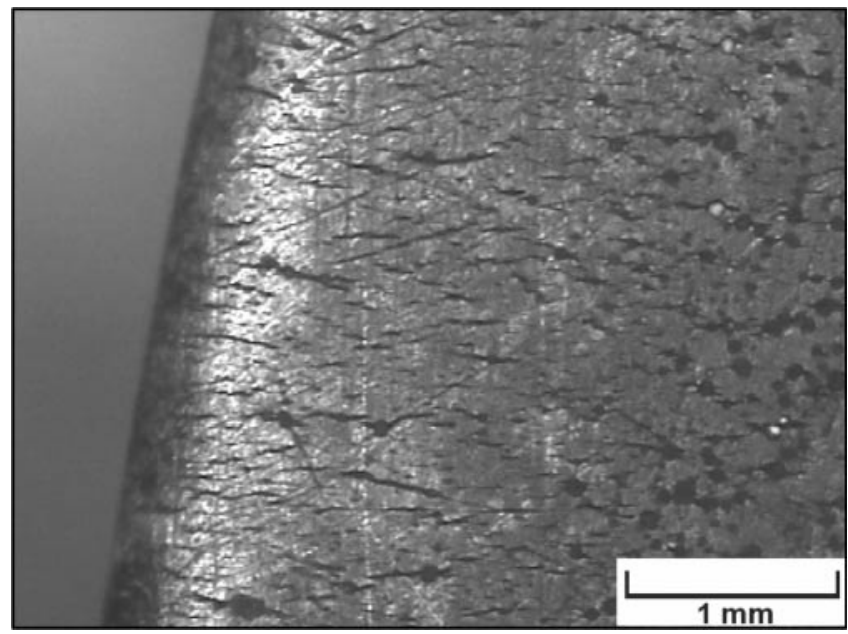

Fig. 10 Specimen after 220000 cycles

up to 300000 . The reason for the large increments was because the material was a hot-work steel having a metallurgy tailored to resist thermal and elevated temperature conditions. Therefore, cracks were not expected within 90000 cycles.

\subsection{Thermal fatigue results}

Typically, an aluminium high-pressure die-casting tool will suffer from fatigue cracking between 100000 and 150000 cycles depending upon the geometry of the die [32]. Signs of cracking in the test specimens began at approximately 180000 cycles, as shown in Fig. 9, and severe cracking began at 220000 cycles, as shown in Fig. 10. It must be noted

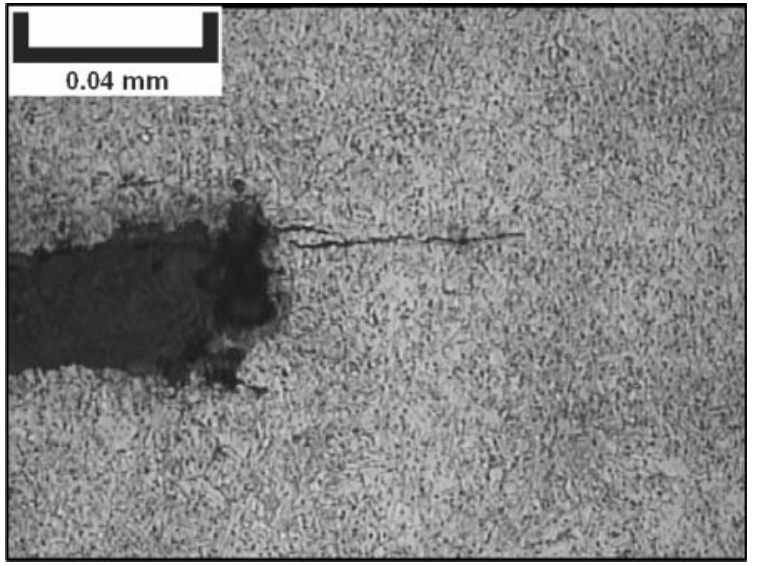

Fig. 11 Crack tip at 300000 cycles

that the experiment only took into account the thermal fatigue aspect of aluminium high-pressure die casting and not other factors, such as pressure, wear, adhesion, ingress, chemical attack, etc., that occur during the casting process and promote crack initiation and crack growth in dies. The discrepancy found was probably a result of these additional factors, but the experiment represented the thermal fatigue element of the process.

The thermal fatigue test, however, produced cracking with the same characteristic pattern of crazed cracking as that found in hot-working dies $[33,34]$.

Figure 11 shows a crack in a specimen, with smaller cracks propagating from the end of it.

\section{DISCUSSION}

A new method of thermal fatigue testing was developed to establish a means of comparing materials and determining their suitability for tooling in aluminium high-pressure die casting. At the commencement of the work, searches of the British and American standards revealed that no thermal fatigue test for this existed. This was thought to be due to the different variables involved that affect the thermal fatigue resistance of materials; e.g. the shape of the specimen, different heating and cooling media, the shape of the thermal cycle, the maximum and minimum temperatures, etc. However, when undertaking a final search of the American standards during the final stages of this work, a Japanese industrial standard [35] and a Chinese standard [34] were identified. In spite of the standard dates (1992 and 1995), they had only recently been placed in the American standards (Chinese standard GB/T 15824-1995 still has a new tag on the American standards website [36]). Unfortunately, no information could be gained from the Chinese standard as it has 
not been translated. However, the Japanese industrial standard by coincidence is identical to the test method developed in this work. It employs the same specimen and edge radius, and employs an automated transfer system, but is does not identify the means of heating or cooling, with the exception of water. It does recommend that, if cooling in water, the temperature should be maintained below $30^{\circ} \mathrm{C}$; this research maintained the water temperature below $25^{\circ} \mathrm{C}$.

Although the new test does not reproduce the die-casting temperature cycle exactly, the materials were subjected to the same minimum and maximum temperatures experienced in a die. The new test only considered thermal fatigue and not other contributing factors associated with die casting such as pressure, erosion, wear, chemical attack, etc. This allowed the thermal fatigue resistance of materials to be compared.

Additional benefits over previous test methods were that the apparatus was versatile in terms of the temperature range $\left(25-1200^{\circ} \mathrm{C}\right)$ and the heating and cooling medium, and the cycle time could be easily controlled. The specimens were small, allowing several to be tested simultaneously, and the geometry allowed easy measurement of cracks. The fatigue apparatus was robust and reliable, which was essential since many thousands of cycles were required.

\section{CONCLUSIONS}

A new test method has been established, enabling the thermal fatigue resistance of materials to be identified. The test is robust, reliable, and versatile and has a large operating temperature range (25$1200{ }^{\circ} \mathrm{C}$ ), and the cycle times and dwell times are adjustable. The results have shown a similar number of cycles to cracking as in actual die-casting tools. Materials can be compared, and an approximate fatigue life for aluminium high-pressure die casting can be determined.

\section{REFERENCES}

1 Chen, Z. W. Formation and progression of die soldering during high pressure die casting. Int. J. Mater. Sci. and Engng, 2005, A397, 356-369.

2 Gulizia, S., Jahedi, M. Z., Doyle, E. D., and Chen, Z. W. Application of duplex surface treatments for aluminium high pressure die casting tools. Tooling 1999 Conference Proceedings, Melbourne Institute of Materials Engineering, Australia, 1999, pp. 205-210.

3 Sjoström, J. and Bergström, J. Thermal fatigue testing of chromium martensitic hot work tool steel after different austenitising treatments. J. Mater. Processing Technol., 2004, 153-154, 1089-1096.
4 Wallace, J. F., Wang, Y., and Schwam, D. Effect of composition and processing on the thermal fatigue and toughness of high performance die steels. Die Casting Engr, September-October 1997, 41, 26-32.

5 Wallace, J. F., Xiaofeng, S. U., and Schwam, D. Die materials of critical applications and increased production of castings. Die Casting Technology for the New Century 2000 Transactions, Rosemont, Illinois, 6-8 November 2000 (North America Die Casting Association (NADCA)).

6 Xiaoxia, H., Hua, Y., Yan, Z., and Fuzhen, P. Effect of Si on the interaction between die casting die and aluminium alloy. J. Mater. Lett., 2004, 58, 3424-3427.

7 Zhu, Y., Schwam, D., Wallace, J. F., and Birceanu, S. Evaluation of soldering, washout and thermal fatigue resistance of advanced metal materials for aluminium die-casting dies, Int. J. Mater. Sci. and Engng., 2004, A379, 420-431.

8 Norwood, A. J. Thermal fatigue of rapid tooling materials. PhD Thesis, Loughborough, 2006.

9 Schwam, D., Wallace, J. F., and Birceanu, S. Effect of design factors on thermal fatigue cracking of die casting dies, Final report, Department of Materials Science, Case Western Reserve University, Cleveland, Ohio, Project DE-FC07-00ID138486, US Department of Energy, Washington, DC, October 2004.

10 Novovic, D., Dewes, R. C., Aspinwall, D. K., Voice, W., and Bowen, $\mathbf{P}$. The effect of machined topography and integrity on fatigue life. Int. J. Mach. Tools and Mf., 2004, 44, 125-134.

11 Persson, A. Tool failure in die casting. Doctoral Thesis, Department of Materials Science, Uppsala University, 2003.

12 Srivastava, A. A multilayer coating architecture to reduce heat checking of die surfaces. Int. J. Surf. and Coatings Technol., 2003, 163-164, 631-636.

13 Srivastava, A., Joshi, V., and Shivpuri, R. Computer modelling and prediction of thermal fatigue cracking in die-casting tooling. Int. J. Wear, 2004, 256, 38-43.

14 Olive, S. Long-life die design. Diecasting World, 2005, 14(1), 15.

15 Bendyk, J. C., Maracz, O. J., and Wallace, J. F. Thermal fatigue behaviour of die materials for aluminium die casting. 6th SDCE International Die Casting Congress, Cleveland, Ohio, 16-19 November 1970, paper 111, pp. 1-20.

16 Badger Metals, http://www.badgermetal.com/ newsletters/1997-03.htm (accessed 24 January 2005).

17 Weroński, A. and Hejwoski, T. Thermal fatigue. In Thermal fatigue of metals, 1991, pp. 108-135 (Marcel Dekker, New York).

18 Worbye, J. New information points the way to longer die casting die life. Die Casting Engr, 1985, 29(4), 42-54.

19 Hartman, G. A thermal control system for thermal cycling. J. Test Evaluation, 1985, 13(5), 363-366.

20 Taira, M., Fujino, M., and Ohtani, R. Collaborative study on thermal fatigue properties of high temperature alloys in Japan. J. Fatigue and Fracture Engng Mater. and Struct., 1979, 1, 495-508.

21 Fissolo, A., Marini, B., Nais, G., and Wident, P. Thermal fatigue behaviour for a 316L type steel. J. Nucl. Mater., 1996, 233-237(1), 156-161. 
22 Persson, A., Hogmark, S., and Bergstrom, J. Thermal fatigue cracking of surface engineered hot work tool steels. Int. J. Surf. and Coatings Technol., 2005, 191, 216-227.

23 Kawamoto, M., Tanaka, T., and Nakajima, H. Effect of several factors on thermal fatigue. J. Mater., 1966, 1(4), 719-758.

24 Glenny, E., Northwood, J. E., Shaw, S. W. K., and Taylor, T. A. A technique for thermal-shock and thermal-fatigue testing based on the use of fluidised solids. J. Inst. Metals, 1959, 87, 294-302.

25 Fatigue and fracture, Vol. 19, 1996, (American Society for Metals, Metals Park, Ohio).

26 Castelli, M. G. and Ellis, J. R. Improved techniques for thermo-mechanical testing in support of deformation modeling. In Thermo mechanical fatigue behavior of materials (Ed. H. Senitoglu), 1993, pp. 195-211 (American Society for Testing and Materials, Philadelphia, Pennsylvania).

27 Van Heerden, C., Nobel, A. P. P., and Van Krevelen, D. W. Mechanism of heat transfer in fluidized beds. Industrial and Engng Chem., 1953, 45(6), 1237.

28 Mowbray, D. F. and McConnelee, J. E. Nonlinear analysis of a tapered disk thermal fatigue specimen, In Thermal fatigue of materials and components, 1976, pp. 10-29 (American Society for Testing and Materials, Philadelphia, Pennsylvania).

29 Persson, A., Hogmark, S., and Bergstrom, J. Simulation and evaluation of thermal fatigue cracking of hot work tool steels. Int. J. Fatigue, 2004, 26, 1095-1107.

30 Persson, A., Hogmark, S., and Bergstrom, J. Temperature profiles and conditions for thermal fatigue cracking in brass die casting dies. J. Mater. Processing Technol., 2004, 152, 228-236.

31 Oberg, E., Franklin, D. J., Holbrook, L., and Henry, H. P. Machinery's handbook, 25th edition, 1996 (Industrial Press, New York).

32 Clegg, A. J. Precision casting processes, 1991, pp. 42-43 (Pergamon Press, New York).

33 Starling, C. M. D. and Branco, J. R. T. Thermal fatigue of hot work tool steel with hard coatings. Int. J. Thin Solid Films, 1997, 308-309, 436-442.

34 Chinese Standard GB/T 15824-1995, Thermal fatigue testing method for hot die steel (in Chinese).

35 JIS Z 2278, Method of thermal fatigue testing for metallic materials, Japanese Industrial Standards Association, Tokyo, Japan, 1992.

36 ANSI, American Standards, e standards store search, http://webstore.ansi.org/ansidocstore/find.asp? (accessed 6 February 2006). 